\title{
秦岭太白山木本植物物种多样性的梯度 格局及环境解释
}

\author{
唐志尧 方精云 张 玲
}

(北京大学环境学院生态学系, 北京大学生态学研究与教育中心, 北京大学地表过程分析与模拟教育部重点实验室, 北京 100871)

\begin{abstract}
摘要: 物种多样性沿环境梯度的分布格局是生物多样性研究的重要议题,而海拔梯度包含了各种环境因子的综合 影响，因此对于探讨物种多样性沿环境梯度的分布格局具有重要意义。秦岭山脉地处我国暖温带向亚热带的过渡 带, 其植被垂直带和物种多样性分布格局对于研究我国南北部植被分异特征具有重要意义。基于对秦岭山脉太白 山南北坡海拔 $1200-3750 \mathrm{~m}$ 之间的垂直样带调查的 83 个样方, 本文利用植被数量分析方法 (DCA 和 TWINSPAN) 和 Shannon-Wiener 多样性指数、Pielou 指数以及 J accard 相异性系数对太白山木本植物物种多样性在 南北坡沿海拔梯度分布格局进行了初步研究。结果表明: 太白山的木本植物群落具有明显的环境梯度格局,海拔 是决定太白山植物群落分布的主要因素, 而坡向起到次要作用。植物群落类型与坡向的关系不大,当考虑群落的 环境梯度格局时,DCA 第一轴主要与年均温密切相关, 而第二轴则取决于年平均相对湿度。乔木层和灌木层的物 种具有相似的海拔梯度格局, 植物群落中木本植物物种丰富度和多样性随着海拔的升高单调下降; 群落均匀度随 着海拔变化的规律不明显; 灌木层的物种多样性比乔木层更为丰富,而南坡具有比北坡更多的物种数和更高的多 样性。相邻海拔之间群落的相异性在南北坡具有不同的分布格局, 在北坡 $2800 \mathrm{~m}$ 以下, 群落相异性沿海拔梯度变 化不大, 而在 $2800 \mathrm{~m}$ 以上的高海拔地区, 群落相异性随海拔的升高而降低; 在南坡, 随着海拔的升高, 群落相异性 不断减少。太白山南坡群落比北坡分布更连续。
\end{abstract}

关键词: DCA, TWINSPAN ,环境梯度, 海拔

中图分类号：Q948 文献标识码：A 文章编号 : 1005-0094(2004) 01-0114-09

\section{Patterns of woody plant species diversity along environmental gradients on Mt. Taibai, Qinling Mountains}

\author{
TAN G Zhi- Yao , FAN G Jing- Yun, ZHAN G Ling \\ Department of Ecology, College of Environmental Sciences, Center for Ecological Research \& Edu- \\ cation, and Key Laboratory for Earth Surface Processes of the Ministry of Education, Peking Uni- \\ versity, Beijing 100871
}

\begin{abstract}
The variation of species diversity along ecological gradients is one of the focuses in the studies of biodiversity. Incorporating multiple interacting resource gradients, altitude gradient may be a decisive factor determining spatial patterns of species diversity. The Qinling Mountains represent the ecotone between warm temperate and subtropical zones in east China, and also play an important role in the study of vegetation differentiation between North and South China. Based on 83 plots of $600 \mathrm{~m}^{2} \mathrm{a}^{-}$ long two altitudinal transects between $1200 \mathrm{~m}$ and $3750 \mathrm{~m}$ a. s. 1. on southern and northern slopes of Mt. Taibai, Qinling Mountains, Central China, we applied multivariate and traditional approaches to analyze the altitudinal patterns of woody plant diversity. The data matrix composed of 192 woody plants from 83 plots was subjected to TWINSPAN and DCA. The classification and ordination of the samples indicated that altitude and mean annual temperature (MAT) were the primary determinants of the floristic composition, followed by exposure and relative humidity $(\mathrm{RH})$. In contrast, slope played
\end{abstract}

* 基金项目 : 国家重点基础研究发展规划( G2000046801) 和国家自然科学基金项目资助 (39830050 和 39970044) 
a minor role in the determination of community distribution. Species richness and diversity of tree and shrub layers declined monotonically with elevation, which reflected decreasing temperature, while the evenness of each community changed little along the altitudinal gradient. With regards to environmental variables, species richness and diversity were primarily controlled by MAT and secondarily by RH. Species diversity was higher on the southern slope than on the northern slope of Mt. Taibai, and also higher in the shrub layer than in the canopy layer. $\beta$ diversity decreased with the increasing of elevation on the southern slope, while it exhibited different patterns at higher and lower elevations on the northern slope: when lower than $2800 \mathrm{~m}$, no significant relationship between altitude and diversity was detected, while at higher elevations, community dissimilarity decreased with the increasing elevation, indicating that communities at lower elevations had a higher rate of floristic turnover than those at higher elevations.

Key words : DCA, elevation, environmental gradient, TWINSPAN

作为生物多样性的本质内容, 物种多样性随着 环境梯度的分布格局受到生态学家的关注 ( Kratochwil , 1999)。基于这一考虑,贺金生和陈伟烈 (1997) 认为, 在区域尺度上影响物种多样性分布格 局的生态因子可以归纳为以下四类：(1) 可作为资 源的生态因子;（2）对植物有直接生理作用的生态 因子,但不能作为资源被消费; (3) 干扰及异质性; （4）生物因子。这些生态因子之间具有不同程度的 相关性, 在探讨多样性的梯度特征时很难加以区分。 纬度梯度和海拔梯度由于包含了各种环境因子的综 合作用而成为环境梯度综合影响的有效替代梯度 (Gaston, 2000)。研究表明, 沿环境梯度, 不同生活 型的物种多样性差异较大, 而木本植物具有比草本 植物更为明确的分布格局 (O'Brien ,1993)。因此研 究木本植物多样性沿海拔梯度的分布格局, 有助于 探讨生物多样性沿海拔梯度分布格局的一般规律。

秦岭山脉地处我国暖温带和亚热带的生态过渡 带 (中国植被图编委会, 2001) , 其植被垂直带的分布 对于我国南北部植被分异研究具有重要的意义。就 植物区系而言, 秦岭山脉是我国种子植物分布的特 有中心之一,有种子植物 158 科 892 属 3124 种,其 中中国特有种 1620 种(占全部物种的 $51.9 \%$ ), 秦岭 特有种 192 种 (6.1\%), 而在 892 属中 39 属为中国 特有 (应俊生, 1994 ; 傅志军等, 1996)。对于太白山 植物群落的多样性, 对不同的植被类型中物种多样 性及群落结构的研究较多 (傅志军, 郭俊理, 1994; 岳明, 周虹霞 ,1997); 应俊生等 (1990) 则系统分析了 太白山植物区系的特征及起源, 但缺乏对物种多样 性沿整个海拔梯度分布的分析。本项研究以秦岭主 峰太白山南北坡 83 个样方为基础, 分析了暖温带山
地木本植物物种多样性沿海拔梯度的分布格局, 并 探讨了形成这些格局的环境解释。

\section{1 自然概况}

太白山为秦岭主峰, 地处 $33^{\circ} 49^{\prime} 31^{\prime \prime} \mathrm{N}-34^{\circ} 08^{\prime} 11^{\prime \prime} \mathrm{N}$, $10741^{\prime} 23^{\prime \prime} \mathrm{E}-10751^{\prime} 40^{\prime \prime} \mathrm{E}$ 之间, 在太白山自然保护区的 $500 \mathrm{~km}^{2}$ 面积以内, 共记录有种子植物 121 科 628 属 1550 种,包括 40 个太白山特有种和 55 个秦岭特有种(傅志军 等,1996)。太白山植被类型丰富, 植被垂直带谱完整,垂 直地带性明显, 根据植物群落的外貌、种类组成、群落结 构及环境特征,由下向上依次分布有: (1) 落叶阔叶林 带: 包括栓皮栋 (Quercus variabilis) 林、锐齿葪栎 ( $Q$. aliena var. acuteserrata) 林、辽东栋 ( $Q$. liaotungensis) 林; (2)落叶小叶林带: 包括䊁皮桦 (Betula utilis) 林、红桦 (Betula albosinensis) 林; (3) 暗针叶林带: 巴山冷杉 ( $A$ bies fargesii) 林; (4) 明亮针叶林带: 太白红杉 (Larix potaninii var. chinensis) 林; (5) 高山灌从草甸带。与此相 对应, 土壤类型沿海拔梯度具有明显的垂直分布梯度, 从 低到高依次分布着山地棕壤、山地暗棕壤、亚高山森林草 甸土、高山草甸土等土壤类型(方正, 高淑贞, 1963 ; 应俊 生等, 1990 ; 应俊生, 1994; 傅志军等, 1996)。太白山南北 坡的气候差异较大,处于南坡的佛坪年降水 $910.6 \mathrm{~mm}$, 年均温 $11.4{ }^{\circ} \mathrm{C}$; 而在北坡的宝鸡年降水为 $694.2 \mathrm{~mm}$, 年 均温 $13^{\circ} \mathrm{C}($ 图 1)。

\section{2 研究方法}

\section{1 数据收集}

在太白山北坡海拔 $1200 \mathrm{~m}$ 、南坡海拔 $1500 \mathrm{~m}$ 以上, 沿海拔梯度每隔 $50 \mathrm{~m}$ 设置 $600 \mathrm{~m}^{2}$ 样方一个, 


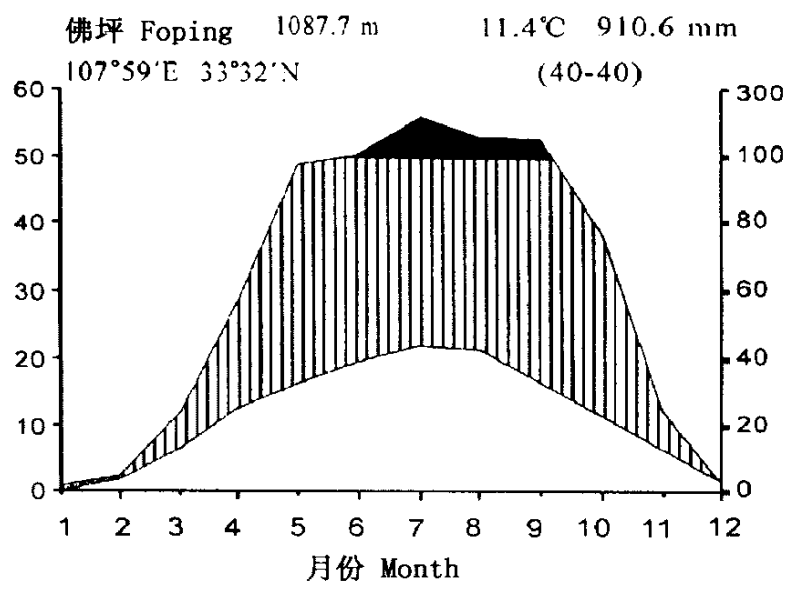

南坡 Southern slope

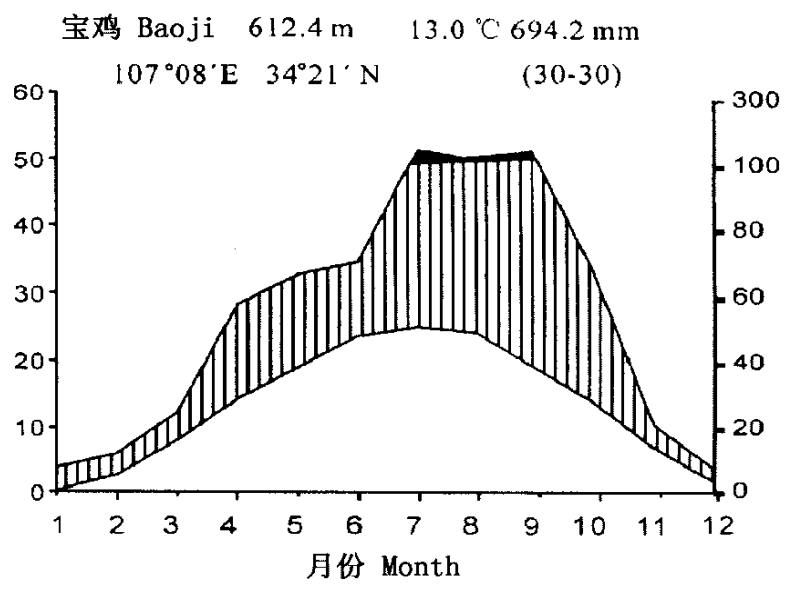

北坡 Northern slope

图 1 秦岭太白山区南北坡气候特征

Fig. 1 Climate diagram of southern and northern slopes of Mt. Taibai, Qinling Mountains

样方选择具有地带性植被的区域。在此以内, 对乔 木层物种进行每木调查并记录样方中出现的灌木物 种; 在 $600 \mathrm{~m}^{2}$ 范围内选取一个 $100 \mathrm{~m}^{2}$ 的范围进行 灌木样方的调查, 记录每个物种的丛数、高度、盖度, 同时记录样方内所出现的所有物种; 在海拔 3400 $\mathrm{m}$ 以上,地带性植被类型为高山灌丛,取样面积为 $100 \mathrm{~m}^{2}$ 。在调查中记录样地海拔、坡度、坡向。共调 查样地 83 个。

\section{2 温度和湿度的测定}

样地所在海拔的年均温和相对湿度可以依据太 白山区的气候特征获取。基于太白山南北坡 18 个 观测点 2001 年 7 月 - 2002 年 7 月的气温、湿度数 据, 我们分析了太白山区气温和湿度在南北坡沿海 拔的分布特征。年均温 (MAT) 与海拔高度 (ALT) 呈显著的负相关：

在南坡 $, \mathrm{MAT}=-0.0037 \cdot \mathrm{AL} \mathrm{T}+14.5,\left(R^{2}=\right.$ $0.92, P<0.001)$;

北坡, $\mathrm{MAT}=-0.0049 \cdot \mathrm{AL} \mathrm{T}+17.9,\left(R^{2}=0\right.$. $99, P<0.001)$ 。

相对湿度 $(\mathrm{RH})$ 与海拔的关系较为复杂: 南坡 相对湿度随海拔升高先降低后增加; 而在北坡, 海 拔 $1500 \mathrm{~m}$ 以上, 相对湿度随海拔升高而增加, 在 $1500 \mathrm{~m}$ 以下, 相对湿度变化不大。相对湿度沿海拔 的变化规律如下:

南坡, $\mathrm{RH}=9 \times 10^{-6} \cdot(\mathrm{AL} \mathrm{T})^{23} / 0.045 \cdot \mathrm{AL} \mathrm{T}+$ 132. 47 ( $\left.R^{2}=0.69, P=0.016\right)$;

北坡, $\mathrm{RH}=0.4 \times 10^{-6} \cdot(\mathrm{ALT})^{2}-0.0153$.

$\mathrm{AL} \mathrm{T}+83.7\left(R^{2}=0.95, P<0.001\right)$ 。
根据这些特征,可以推算出各个样地的温度、湿 度条件。

\section{3 植被分析}

利用去势对应分析 (DCA) 对乔木层和灌木层的 重要值进行群落的排序, 同时以二元指示种分析 (TWINSPAN) 对木本植物进行分类 (Hill, 1979; Hill \& Gauch Jr.，1980）。将 DCA 排序第一轴和第 二轴的排序值与海拔、坡度、坡向、年均温和相对湿 度等环境参数进行相关分析, 以探讨植物群落与环 境因子之间的关系, 同时分析物种多样性与各环境 参数以及与 DCA 第一轴、第二轴排序值之间的关 系。

多样性测度 : 物种丰富度指样地中出现的物种 数 $S$,多样性以 Shannon-Wiener 指数 $\left(H^{\prime}\right)$ 表示, 物 种均匀度采用 Pielou 指数 $\left(J_{s w}\right)$ 测度; $\beta$ 多样性以 $\mathrm{J}$ accard 相异性系数 $\left(\boldsymbol{\beta}_{c j}\right)$ 表示。各指数的计算公式 为:

$$
\begin{aligned}
H^{\prime} & =-\sum P_{i} \log P_{i} \\
J_{s w} & =\left(-\sum P_{i} \log P_{i}\right) / \log S \\
\beta_{c j} & =1-2 j /(a+b)
\end{aligned}
$$

式中, $S$ 为样地中的物种总数, $P_{i}$ 为第 $i$ 个物种的 相对重要值 IV $=($ 相对多度 + 相对盖度 + 相对高 度) $/ 3, a$ 和 $b$ 分别为两个相邻样方所出现的物种 数, $j$ 为两个样方所共有的物种数 (Whittaker, 1972；方精云等,2004）。

\section{3 结果与讨论}

\section{1 物种组成}


在调查中共记录种子植物 78 科 254 属 586 种, 其中木本植物 192 种 (32.8\%), 草本植物 394 种 (67. $2 \%) 。 600 \mathrm{~m}^{2}$ 样方内的平均物种数为 $43.5 \pm 16$ 种, 最多为 73 种, 最少为 19 种。在这 586 种植物中, 高 位芽植物占 32.8\%(192 种)，以下依次为地面芽 (186 种, $31.7 \%)$ 、一年生植物 (113 种, $19.3 \%$ )、地下芽 (50 种, $8.5 \%$ ) 以及地上芽 (45 种, $7.7 \%$ )。各种生活型物 种的比例随着海拔梯度不断变化, 大致的趋势为一年 生植物的比例随海拔的升高而增加, 而高位芽植物的 比例则随海拔升高急剧下降, 其他类型沿海拔梯度变 化不明显 (图 2)。一年生植物在海拔 $2000 \mathrm{~m}$ 以下仅 占约 $8 \%$, 但随着海拔的升高, 在 $3100 \mathrm{~m}$ 以上,一年生 植物的比例逐渐增加到 $30 \%$ 左右; 而高位芽植物在 北坡 $1600 \mathrm{~m}$ 以下, 南坡 $1800 \mathrm{~m}$ 以下时,约占总种数 的 $60 \%$ 左右, 但在 $3300 \mathrm{~m}$ 以上时仅占 $10 \%$ 左右。其 他生活型的物种比例虽然在不同海拔有波动, 但沿海 拔梯度的总体变化不大, 地上芽、地面芽和地下芽植 物分别占 5\%、10\%和 $30 \%$ (图 2)。

群落的优势树种沿海拔梯度不断变化,形成互 相更替的格局, 并且在不同的群落之间互相重叠, 形 成群落交错带。在南坡的中低海拔地区, 特别是海 拔 $1800-2400 \mathrm{~m}$ 之间, 由于各海拔段出现的树种相 对较多, 而各个物种的优势度不很明显, 植物群落沿 海拔梯度呈现一种连续变化的格局; 而在北坡, 由 于物种数相对较少, 各海拔段的优势物种较为明显, 群落的交错特征不很明显, 不同群落之间的更替主 要以突变为主 (图 3)。

\section{2 群落的分类与排序}

依据 TWINSPAN 聚类结果,太白山海拔 1200

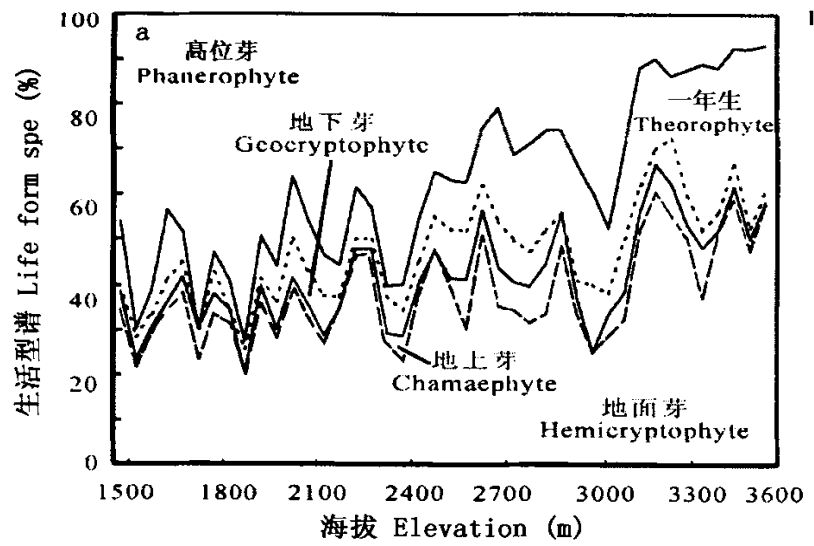

$\mathrm{m}$ 以上的植物群落可以划分为以下类型: 锐齿葪栎 林、辽东柇林、红桦林、粮皮桦林、巴山冷杉林、太白 落叶松林以及高山灌丛, 群落分类的结果与以往传 统研究的结果比较一致。DCA 前四个排序轴的特 征值分别为 $0.88 、 0.47 、 0.33$ 和 0.21 , 第一轴的特 征值比其他轴大得多, 说明第一轴在群落物种组成 上具有决定性的作用。各植物群落沿 DCA 排序轴 上的格局如图 4 , 沿着 $\mathrm{AX} 1$ 轴, 按排序值从低到高 依次分布着柇林 (包括锐齿檞柇林和辽东栎林) 、红 桦林、粘皮桦林、巴山冷杉林、太白落叶松林和高山 灌丛, 这一顺序与各群落类型沿海拔梯度的分布顺 序一致; 而辽东栎林和锐齿葪栎林因在第一轴重 叠, 而只能依据第二轴分开, 说明辽东栎林和锐齿䚞 柇林在物种组成上有密切的关系。沿第二轴, 只分 布于北坡的辽东栋林的排序值比锐齿葪栋林大。各 环境参数与排序轴之间的相互关系表明, 海拔、年均 温、年平均相对湿度与 DCA 排序第一轴具有显著的 相关性; 而坡向和相对湿度则与 DCA 排序第二轴 显著相关 (表 1)。这一结果表明, 在太白山海拔梯 度和坡向是决定植物群落分布的主要因素, 而坡度 对群落的分布影响不显著。在太白山区, 海拔同时 体现了温度和水分的变化特征: 在南北坡, 随着海 拔的升高, 年均温不断降低, 而相对湿度在南坡随海 拔的升高先减少后增加, 在北坡则随海拔升高不断 增加。而坡向在很大程度上体现了湿度的差异: 南 坡比北坡更为潮湿。因此,太白山区木本物种组成 主要取决于温度梯度, 而湿度梯度起次要的作用。 各群落类型沿 AX1 和 AX2 轴相互重叠, 说明各个 群落之间并非截然分开,而具有相互交错的特征。

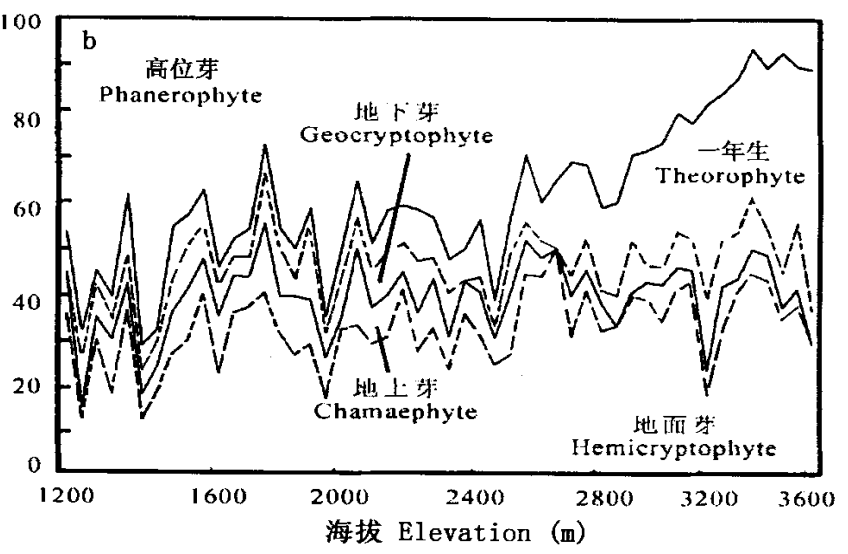

图 2 不同生活型组成沿海拔梯度的变化规律 (a. 北坡; b. 南坡)

Fig. 2 Life form composition along an altitudinal gradient (a) northern slope, and (b) southern slope 


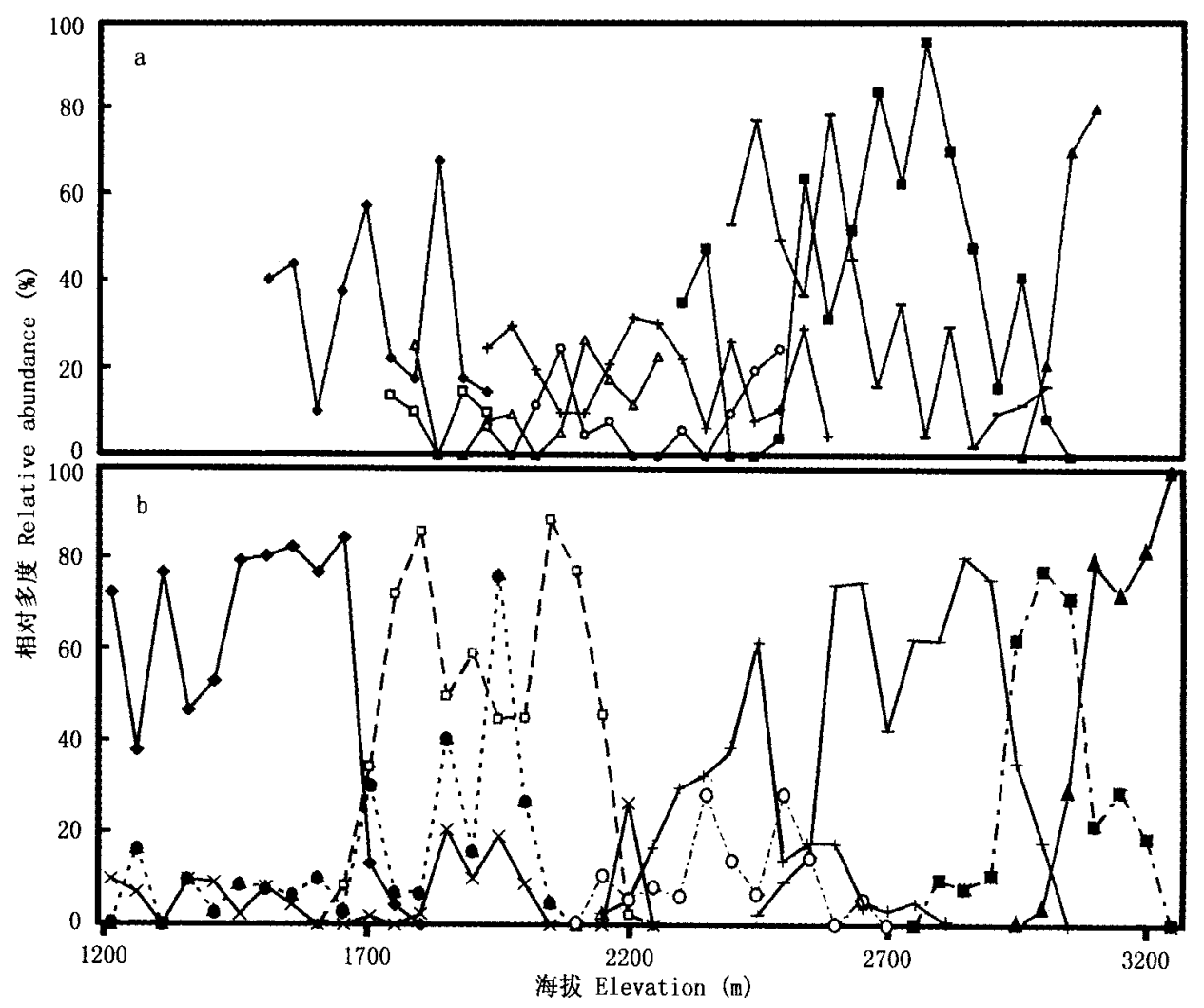

图 3 太白山南北坡常见乔木相对多度沿海拔的变化规律

Fig. 3 Altitudinal distribution of some common taxa along (a) the southern and (b) northern slope of Mt. Taibai, Qinling Mountains

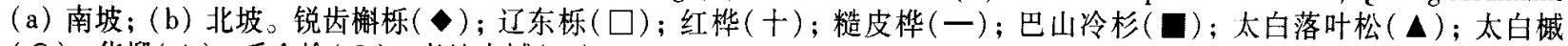
$(O)$; 华椴 $(\triangle)$; 千金榆 $(\bullet)$; 青蛙皮械 $(x)$

Quercus aliena var. acuteserrata $(\bullet)$; Q. liaotungensis $(\square)$; Betula albo-sinensis $(+) ;$ B. utilis $(-)$; Abies fargesii $(\boldsymbol{\square})$; Larix chinensis $(\Delta)$; Acer giraldii $(O)$; Tilia chinensis $(\triangle)$; Carpinus cordata $(\bullet)$; Acer grosser $(x)$

表 1 DCA 排序第一轴、第二轴,环境变量以及多样性之间的相互关系 $(r)$

Table 1 The correlation among DCA axes, environmental variables and diversity indices

\begin{tabular}{|c|c|c|c|c|c|c|c|c|}
\hline & $\mathrm{AX} 1$ & $\mathrm{AX} 2$ & $\begin{array}{c}\text { 灌木层物种数 } \\
S \text {-shrub }\end{array}$ & $\begin{array}{c}\text { 乔木层物种数 } \\
S \text {-tree } \\
\end{array}$ & $\begin{array}{c}\text { 灌木层多样性 } \\
H^{\prime} \text {-shrub }\end{array}$ & $\begin{array}{c}\text { 乔木层多样性 } \\
H^{\prime} \text {-tree }\end{array}$ & $\begin{array}{c}\text { 灌木层均匀度 } \\
J_{s w} \text {-shrub } \\
\end{array}$ & $\begin{array}{c}\text { 乔木层均匀度 } \\
J_{s w} \text {-tree } \\
\end{array}$ \\
\hline $\begin{array}{l}\text { 海拔 } \\
\text { AL T }\end{array}$ & $\begin{array}{c}0.92, \\
P<0.001\end{array}$ & $\begin{array}{c}0.14 \\
P=0.20\end{array}$ & $\begin{array}{c}-0.78 \\
P<0.001\end{array}$ & $\begin{array}{c}-0.63 \\
P<0.001\end{array}$ & $\begin{array}{c}-0.79 \\
P<0.001\end{array}$ & $\begin{array}{c}-0.68 \\
P<0.001\end{array}$ & $\begin{array}{c}-0.28 \\
P=0.01\end{array}$ & $\begin{array}{c}-0.03 \\
P=0.79\end{array}$ \\
\hline $\begin{array}{l}\text { 坡向 } \\
\text { ASPE }\end{array}$ & $\begin{array}{c}0.24 \\
P=0.29\end{array}$ & $\begin{aligned} & 0.73, \\
P & <0.001\end{aligned}$ & $\begin{array}{c}0.1 \\
P=0.37\end{array}$ & $\begin{array}{c}0.24 \\
P=0.04\end{array}$ & $\begin{array}{c}0.05 \\
P=0.65\end{array}$ & $\begin{array}{c}0.20 \\
P=0.09\end{array}$ & $\begin{array}{c}0.04 \\
P=0.72\end{array}$ & $\begin{array}{c}0.21 \\
P=0.08\end{array}$ \\
\hline $\begin{array}{l}\text { 坡度 } \\
\text { Slope }\end{array}$ & $\begin{array}{l}-0.08 \\
P=0.48\end{array}$ & $\begin{array}{l}-0.10 \\
P=0.36\end{array}$ & $\begin{array}{c}-0.03 \\
P=0.78\end{array}$ & $\begin{array}{c}-0.20 \\
P=0.09\end{array}$ & $\begin{array}{l}-0.003 \\
P=0.98\end{array}$ & $\begin{array}{c}0.21 \\
P=0.07\end{array}$ & $\begin{array}{c}0.04 \\
P=0.72\end{array}$ & $\begin{array}{c}-0.22 \\
P=0.06\end{array}$ \\
\hline $\begin{array}{l}\text { 年均温 } \\
\text { MAT }\end{array}$ & $\begin{array}{l}-0.92 \\
P<0.001\end{array}$ & $\begin{array}{l}-0.23 \\
P=0.03\end{array}$ & $\begin{aligned} & 0.72 \\
P & <0.001\end{aligned}$ & $\begin{aligned} & 0.57 \\
P & <0.001\end{aligned}$ & $\begin{array}{c}0.74 \\
P<0.001\end{array}$ & $\begin{array}{c}0.62 \\
P<0.001\end{array}$ & $\begin{array}{c}0.28 \\
P=0.01\end{array}$ & $\begin{array}{l}-0.004 \\
p=0.97\end{array}$ \\
\hline $\begin{array}{l}\text { 相对湿度 } \\
\mathrm{RH}\end{array}$ & $\begin{array}{c}0.53 \\
P<0.001\end{array}$ & $\begin{array}{c}0.85 \\
P<0.001\end{array}$ & $\begin{array}{c}-0.04 \\
P=0.75\end{array}$ & $\begin{array}{c}0.1 \\
P=0.40\end{array}$ & $\begin{array}{c}-0.15 \\
P=0.17\end{array}$ & $\begin{array}{c}0.03 \\
P=0.81\end{array}$ & $\begin{array}{c}-0.09 \\
P=0.41\end{array}$ & $\begin{array}{c}0.26 \\
P=0.02\end{array}$ \\
\hline $\mathrm{AX} 1$ & & $\begin{array}{c}0.24 \\
P=0.03\end{array}$ & $\begin{array}{c}-0.74 \\
P<0.001\end{array}$ & $\begin{array}{c}-0.77 \\
P<0.001\end{array}$ & $\begin{array}{c}-0.65 \\
P<0.001\end{array}$ & $\begin{array}{c}-0.73 \\
P<0.001\end{array}$ & $\begin{array}{c}-0.25 \\
P=0.02\end{array}$ & $\begin{array}{c}-0.11 \\
P=0.31\end{array}$ \\
\hline AX2 & $\begin{array}{c}0.24 \\
P=0.03\end{array}$ & & $\begin{array}{c}0.17 \\
P=0.12\end{array}$ & $\begin{array}{c}0.15 \\
P=0.19\end{array}$ & $\begin{array}{c}0.06 \\
P=0.60\end{array}$ & $\begin{array}{c}0.12 \\
P=0.32\end{array}$ & $\begin{array}{c}-0.09 \\
P=0.41\end{array}$ & $\begin{array}{c}0.31 \\
P=0.006\end{array}$ \\
\hline
\end{tabular}

\section{3 物种多样性沿海拔梯度的分布}

木本植物物种丰富度沿太白山南北坡随着海拔 的升高而单调下降。分布在最下部的锐齿葪栎林具 有最高的物种多样性,每 $600 \mathrm{~m}^{2}$ 的样方面积内有
25 - 30 种木本植物; 而在 $3400 \mathrm{~m}$ 以上的高山灌丛 仅有 3-4 个灌木物种。物种丰富度的垂直递减率在 南、北坡有较大差异: 在南坡,海拔每升高 $100 \mathrm{~m}$,物 种数目平均减少 1.4 种, 而在北坡则平均减少 0.8 


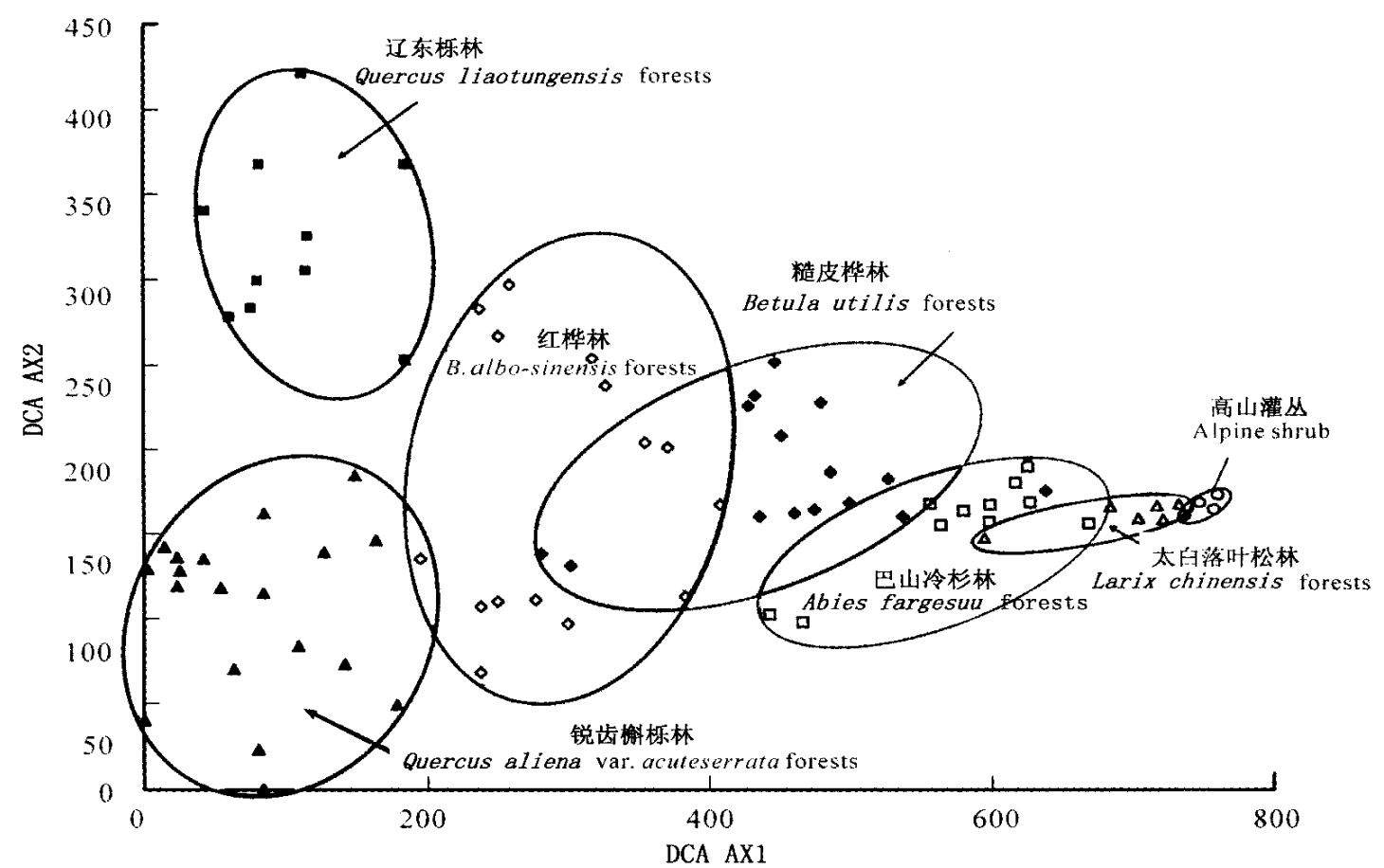

图 4 太白山植物群落沿 DCA 排序第一、第二轴的分布格局, 群落类型基于 TWINSPAN对木本植物重要值的聚类结果

Fig. 4 Distribution pattern of communities along DCA axes 1 and 2 in Mt. Taibai. Community classification is based on TWINSPAN clustering

种。在低海拔地区, 南坡的物种丰富度比北坡大; 而在中高海拔地区, 南、北坡相差不大(图 5)。沿着 海拔梯度, $H^{\prime}$ 与物种丰富度变化规律相似, 即随着 海拔的升高不断降低。不同层次之间物种多样性的 比较结果表明, 乔木层和灌木层的物种丰富度沿着 海拔梯度分布的格局相似,但灌木层的物种丰富度 和多样性比乔木层更为丰富。物种丰富度与环境因 子的相互关系表明, 物种丰富度 $(S)$ 与年平均气温 (MAT) 以及相对湿度 (RH) 显著相关 (MAT： $P<$ $0.001 ; \mathrm{RH}: P=0.002)$, 物种多样性 $\left(H^{\prime}\right)$ 与环境 因子的关系与 $S$ 与环境因子之间的关系相似。当 考虑各层次物种多样性与环境因子之间的关系时， 灌木层和乔木层具有相似的格局, 但灌木层多样性 与气温的相关性比乔木层大。乔木层和灌木层均匀 度指数沿海拔梯度上虽有波动, 但总体上不存在显 著的变化趋势(图 5 ,表 1)。

在不同的水分条件下,木本植物多样性有不同 的决定因子: 在水分充足时, 木本植物多样性与年 均温呈显著的正相关 (Glenn-Lewin, 1977) ; 而在干 旱地区, 水分条件成为限制木本植物分布的主要因 子, 因而多样性与降水量呈正相关关系 (O'Brien, 1993)。在太白山区, 降水并不是限制植物群落分布
的主要因素, 因此物种多样性主要由气温特征决定, 而因为年均温与海拔有显著的负相关关系, 因此, 木 本植物物种多样性与海拔呈负相关。

群落中不同层次的物种多样性有较大差异。在 本研究中, 灌木层的物种丰富度和多样性都高于乔 木层, 这一结果与其他温带森林的研究结果较为一 致(黄建辉等, 1997)。Rey Benayas (1995) 认为, 由 于较小生活型的物种能充分利用局域环境中小尺度 的资源而对环境的空间异质性更为敏感,因而可以 维持更多的物种。在本项研究中, 灌木物种小于乔 木物种, 因而具有更丰富的多样性。

\section{$3.4 \beta$ 多样性的海拔梯度格局}

沿太白山北坡, 木本植物的 J accard 相异性系数 在 $2800 \mathrm{~m}$ 以下变化不大; 在 $2800 \mathrm{~m}$ 以上, 群落相 异性随着海拔的升高而不断降低。相邻群落在海拔 $2800-3000 \mathrm{~m}$ 之间的相异性系数比邻近海拔高, 这 一海拔范围正好对应从落叶阔叶林向暗针叶林的过 渡带。这种趋势说明, $2800 \mathrm{~m}$ 以上的针叶林地带的 生境比低海拔的阔叶林更为均一, 并且海拔越高, 生 境的均一性程度也就越高。在针叶林与阔叶林的交 错带, 相邻海拔的群落之间物种替换速率较高。而 在南坡, 随着海拔的升高, 相邻海拔之间的相异性随 
南坡 Southern slope
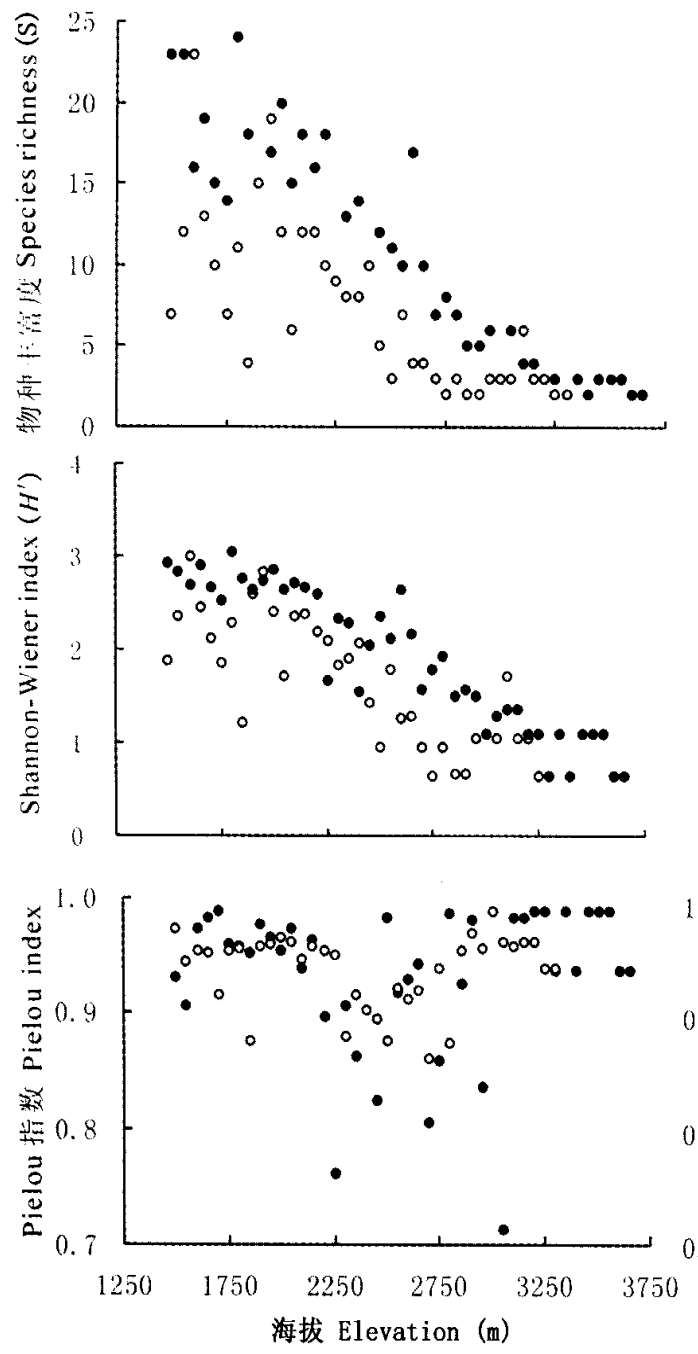

北坡 Northern slope
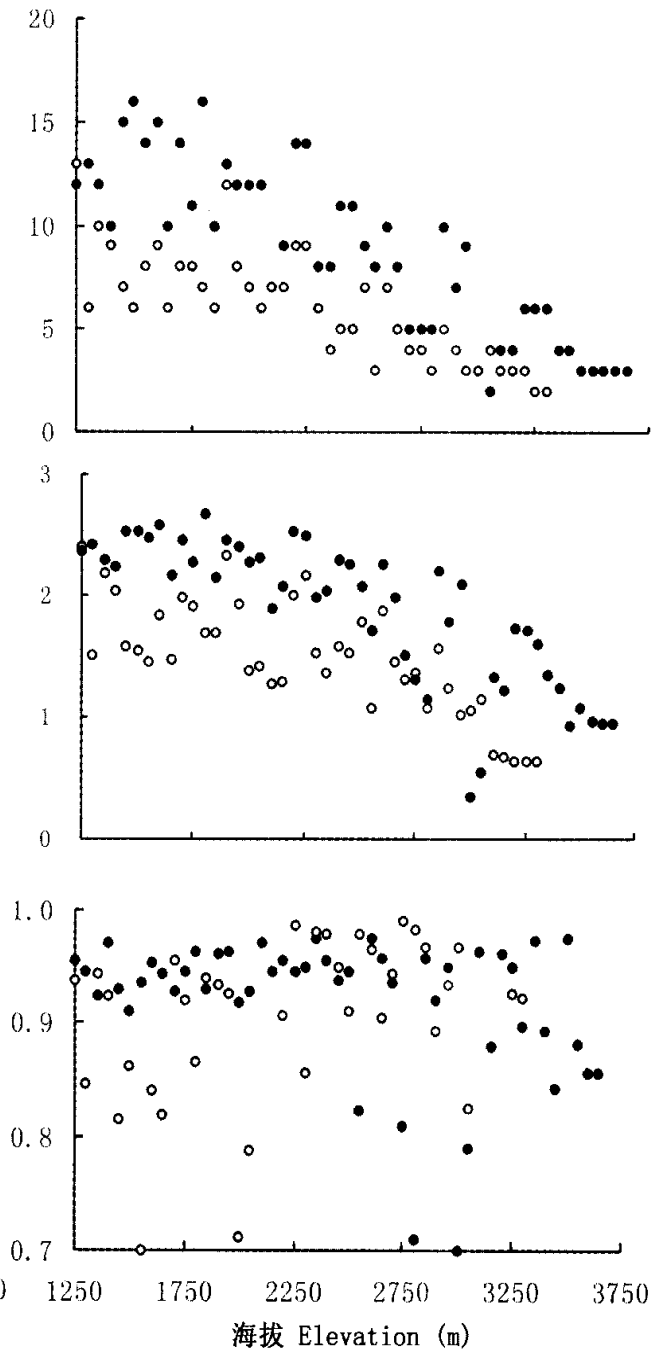

图 5 太白山物种丰富度 $(S)$ ，多样性 $\left(H^{\prime}\right)$ ，均匀度 $\left(J_{s w}\right)$ 随海拔梯度的分布格局灌木层 $(\bullet)$ ，乔木层 $(0)$

Fig. 5 Altitudinal patterns of species richness $(S)$, diversity $\left(H^{\prime}\right)$ and evenness $\left(J_{s w}\right)$ in Mt. Taibai. Shrub layer $(\bullet)$, and tree layer $(\mathrm{O})$.

着海拔的升高不断降低,而且各种不同群落类型之 间不存在类似于北坡的突变带, 说明在南坡各个物 种趋于连续分布 (图 6)。

影响 $\beta$ 多样性的因子主要有土壤异质性、不同 物种之间的竞争以及干扰等因素 (Whittaker et al, 2001）。虽然缺乏定量的研究, 但干扰强度随着海拔 的升高不断地降低是一个客观存在的现象。在太白 山区, 北坡剧烈的人为活动可以上升到海拔 $2800 \mathrm{~m}$ 左右, 中度干扰一方面增加了 $a$ 多样性, 同时也引起 了生境的异质化,因而也增加了 $\beta$ 多样性; 而在南 坡, 人为的干扰相对较弱。因此在中低海拔地区, 北 坡的 $\beta$ 多样性比南坡高。

\section{4 小结}

太白山南北坡木本植物群落及其多样性沿海拔 梯度的分布格局表明: 温度梯度是决定太白山植物 群落组成和分布的主要梯度, 湿度起次要作用; 沿 着海拔梯度, 灌木物种多样性的分布格局与乔木层 物种的多样性格局相似, 两者都随着海拔的升高而 降低, 因而木本植物总数随海拔升高而急剧减少; 灌木层的物种多样性比乔木层大; 群落的均匀度沿 海拔梯度变化不明显。相邻海拔之间群落的物种更 替速率随海拔的关系在南北坡差异较大: 在南坡, 物种更替速率与海拔存在近似的负相关关系; 而 


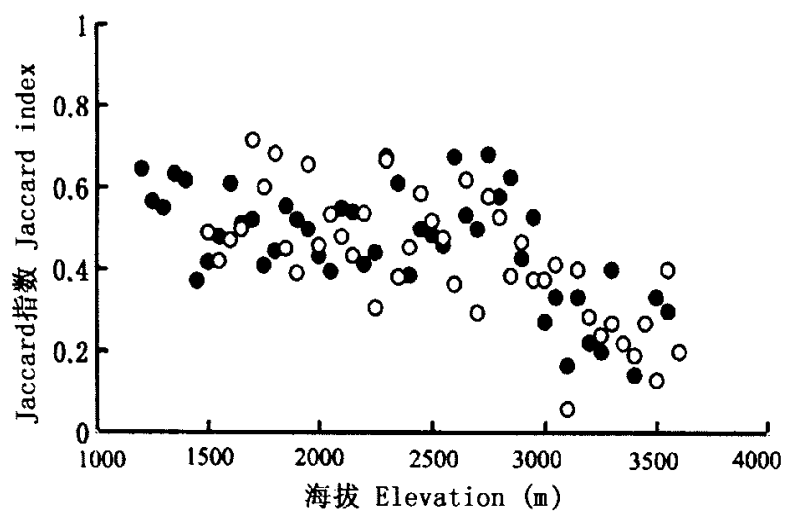

图 6 太白山相邻海拔间群落相异性的海拔梯度格局 ( X 轴 指示相邻样方中的低海拔)

Fig. 6 Altitudinal pattern of community dissimilarity between adjacent elevations in Mt. Taibai ( $X$ coordinate represents the lower elevations of the plot pairs. Southern slope $(\bigcirc)$ and northern slope (

在北坡, 低海拔落叶阔叶林的物种替换速率变化不 大 ; 但在高海拔的地区,物种替换速率随着海拔的 升高而减少, 在针叶林和阔叶林之间的交错带, 群落 间的物种更替速率比邻近海拔群落之间的更替速率 高。

致谢 : 野外工作得到太白山国家级自然保护区管理 局和中国科学院西北植物研究所吴振海高级工程师 的支持和帮助, 参加野外工作的还有韩文轩, 柯金 虎,在此一并致谢。

\section{参考文献}

Editorial board of Vegetation Map of China（中国植被图编委 会). 2001. Vegetation Atlas of China (中国植被图集). Science Press, Beijing.

Fang, J. Y. (方精云), Shen, Z. H. (沈泽昊), Tang, Z. Y. (唐志尧) and Wang, Z. H. (王志恒). 2004. Exploring altitudinal patterns of plant diversity of Chiná s mountains : Peking Universitý s Survey Plan for Plant Species Diversity of Chiná s Mountains and some methodological standards. Biodiversity Science (生物多样性)，12(1)：5-9.

Fang, Z. (方正) and Gao, S. Z. (高淑贞). 1963. On the altitudinal zonation of Mt. Taibai, Qinling Mountains. Acta Phytoecologia et Geobotanica Sinica（植物生态学与地 植物学丛刊), 1- 2: 162 - 163. (in Chinese)

Fu, Z. J. (傅志军), Zhang, X. Y. (张行勇), Liu, S. Y. (刘顺义) and Tao, M. (陶铭). 1996. The summarize of research on the flora and vegetation of the Qinling Mountain Range. Acta Botanica Boreali-Occidentalia Sinica (西北植物学报)，16: 93 - 106. (in Chinese)
Fu, Z. J. (傅志军) and Guo, J. L. (郭俊理)。1994. Preliminary studies of Betula albosinensis forest in Taibai Mountain. Acta Phytoecologica Sinica（植物生态学报）, 18: 261 - 270. (in Chinese)

Gaston, K. J. 2000. Global patterns in biodiversity. Nature, 405 : 220 - 226.

Glenn-Lewin, D. C. 1977. Species diversity in the North American temperate forests. Vegetatio, 33: 153 - 162.

Hamilton, A. C. and Perrott, R. A. 1981. A study of altitudinal zonation in the montane forest belt of Mt. Elgon, Kenya/ Uganda. Vegetatio, 45: 107 - 125.

He, J. S. (贺金生) and Chen, W. L. (陈伟烈). 1997. A review of gradient changes in species diversity of land plant communities. Acta Ecologica Sinca (生态学报), 17: 91 - 99. (in Chinese)

Hill, M. O. 1979. TWINSPAN-A FORTRAN Program for A rranging Multivariate Data in An Ordered Twoway Table by Classification of the Individuals and Attributes. Cornell University, Ithaca, New York.

Hill, M. O. and Gauch, Jr. H. G. 1980. Detrended Corre spondence Analysis: an improved ordination technique. Vegetatio, 42: 47 - 58.

Huang, J. H. (黄建辉), Gao, X. M. (高贤明), Ma, K. P. (马克平) and Chen, L. Z. (陈灵芝). 1997. A comparative study on the species diversity in zonal forest communities. Acta Ecologica Sinica (生态学报)，17：611 618. (in Chinese)

Kratochwil , A. 1999. Biodiversity in ecosystems: some principles. In: Kratochil A. (ed.), Biodiversity in Ecosystems. Kluwer Academic Publishers, Dordrecht , 5 - 38.

Ó Brien, E. M. 1993. Climatic gradients in woody plant species richness : towards an explanation based on an analysis of Southern Africá s woody flora. Journal of Biogeography, 20: 181 - 198.

Rey Benayas, J. M. 1995. Patterns of diversity in the strata of boreal montane forest in British Columbia. Journal of Vegetalion Science, 6: 95 - 98.

Whittaker, R. H. 1972. Evolution of measurement of pecies diversity. Taxon, 21: 213 - 251.

Whittaker, R.J. , Willis, K.J. and Field, R. 2001. Scale and species richness: towards a general, hierarchical theory of species diversity. Journal of Biogeography, 28: 453 470.

Ying, T. S. (应俊生). 1994. An analysis of the flora of Qinling Mountain Range: its nature, characteristics and origins. Acta Phytotaxonomica Sinica（植物分类学报）, 32: 389 - 410. (in Chinese)

Ying, T. S. (应俊生), Li, Y. F. (李云峰), Guo, Q. F. (郭 勤峰) and Cui , H. (崔禾). 1990. Observations on the flora and vegetation of Taibaishan, Qinling Mountain Range, southern Shaanxi, China. Acta Phytotaxonomica Sinica (植物分类学报), 28:261-293. (in Chinese)

Yue, M. (岳明) and Zhou, H. X. (周虹霞) . 1997. Diversity of higher plants in deciduous broadleaved forests on the northern slope of Taibai Mountain. Acta Botanica Yunnanica (云南植物研究), 19: 171 - 176. (in Chinese) 